\title{
Um estudo do consumo de água no ambiente escolar e propostas de intervenções artísticas, para uma sensibilização lúdica
}

\section{A study of water consumption in the school environment with proposals for artistic interventions to raise awareness}

\section{Estudio del consumo de agua en el entorno escolar y propuestas de intervenciones artísticas, para una conciencia lúdica}

Taise Bomfim de Jesus ${ }^{1}$ Alessandro Oliveira Andrade ${ }^{2}$ Carlos Eduardo Veiga de Carvalho

\section{Resumo}

Estudos demonstram que formas mais eficientes de construção do ambiente escolar, deve considerar recursos lúdicos e desvencilhados do livro didático e da tradicional aula expositiva. Inserido nesse contexto, o presente trabalho se propôs a, através de diferentes intervenções artísticas, contribuir com a percepção sobre o uso racional da água, no ambiente escolar. Esta pesquisa realizada no Colégio Georgina de Mello, Feira de Santana Ba, foram divididas em 3 (três) etapas: 1) Fase diagnóstica, que analisou a comunidade e a percepção a respeito de locais com maior uso de água, existência de vazamentos, possíveis ações de redução de uso, e ainda a responsabilidade da gestão do uso, com eficiência, 2) As intervenções artísticas e 3) Diagnóstico, pós- intervenção. Conclui-se que o processo educativo baseado em intervenções artísticas demonstrou novas percepções, além de contar com a participação ativa da comunidade escolar, agregando-a, e permitindo a ampliação do entendimento e importância de todos os atores escolares no controle e gestão do uso da água, no ambiente escolar.

Palavras-chave: Percepção escolar. Uso da Água. Ferramentas lúdicas.

\begin{abstract}
Keywords: School perception. Water Use. Playful tools.

\footnotetext{
1 Universidade Estadual de Feira de Santana.

${ }^{2}$ Mestre pelo PROFCIAMB/UEFS.

${ }^{3}$ Universidade Estadual do Norte Fluminense Darcy Ribeiro.
}

Studies have demonstrated that more efficient ways of building this environment should consider resources that are ludic and detached from the textbook and traditional lecture. Inserted in this context, the present work has proposed, through different artistic interventions, to contribute with the perception about the rational use of water in the school environment. This research was carried from the Georgina de Mello High School, in Feira de Santana - Ba, and was divided into 3 (three) stages: 1) Diagnostic phase, which made perception regarding places with greater use of water, existence of leaks, possible actions to reduce use, and also the responsibility of managing the water use efficiently, 2) Artistic interventions 3) New diagnosis, after the intervention. It is concluded that the educational process based on artistic interventions demonstrated the development of new perceptions, in addition to count with the active participation of the school community, aggregating it and allowing a broader understanding of the importance of all school actors in the control and management of water use in the school environment. 


\section{Resumen}

Los estudios demuestran que las formas más eficientes de construir el ambiente escolar, deben considerar recursos lúdicos y desvinculados del libro de texto y la clase expositiva tradicional. Insertado en este contexto, el presente trabajo se propone, a través de diferentes intervenciones artísticas, contribuir a la percepción sobre el uso racional del agua, en el ámbito escolar. Esta investigación realizada en el Colégio Georgina de Mello, Feira de Santana - Ba, se dividió en 3 (tres) etapas: 1) Fase de diagnóstico, que analizó la comunidad y la percepción sobre lugares con mayor uso de agua, existencia de filtraciones, posibles acciones para reducir el uso, y también la responsabilidad de la gestión del uso, con eficiencia, 2) Intervenciones artísticas y 3) Diagnóstico, posintervención. Se concluye que el proceso educativo basado en intervenciones artísticas demostró nuevas percepciones, además de contar con la participación activa de la comunidad escolar, agregándola y permitiendo ampliar el entendimiento e importancia de todos los actores escolares en el control y gestión de la uso del agua en el entorno escolar. Palabras Clave: Percepción de la escuela. Uso del agua. Herramientas lúdica.

\section{Introdução}

$\mathrm{O}$ atual modelo de desenvolvimento gera enormes consequências socioambientais, trazendo, em sua essência, uma contradição entre a lógica do mercado (estímulo ao consumo, perpassando as necessidades) e o equilíbrio ambiental (LIMA, 1997). O conceito de desenvolvimento sustentável é referente a um processo alternativo, fruto de uma visão crítica em prol da contínua preservação ambiental sem que haja, contudo, oposição ao progresso, funcionando como ponto de equilíbrio entre o bem-estar social, econômico e ecológico, por reconhecer a finitude dos recursos ambientais, sendo, por assim dizer, ético. Não é possível falar em meio ambiente sustentável sem atribuir à Educação Ambiental o compromisso de ser um instrumento essencial para viabilizar o desenvolvimento pleno, sadio e harmônico, segundo os aspectos abordados pela ótica social que envolvem o ecossistema (MASSINE, 2010).

A maior parcela do Planeta Terra é constituída por água. A água salgada é preponderante na superfície. Como ressalta Braga et al. (2002, p.72-73), 96,5\% de toda a água disponível no planeta fazem parte dos oceanos e mares, portanto, é salgada. A água doce representa apenas 3,5\%, e desse total, uma grande quantidade localiza-se em lençóis subterrâneos, geleiras e calotas polares, inacessíveis para a humanidade. Apenas $0,5 \%$ da água, sob o ponto de vista tecnológico e econômico, são exploráveis e, deste percentual, deve-se levar em consideração os locais de difícil acesso, e as pressões antrópicas sobre a qualidade, tornando-a um recurso alvo de preocupação ambiental.

Segundo a ANA (Agência Nacional de Águas) aponta que no Brasil, a demanda por uso de água é crescente e teve um aumento estimado de aproximadamente $80 \%$ no total retirado de água nas últimas duas décadas. Ela ainda faz previsões, como a que segue:

A previsão é de que, até 2030 , essa retirada de água aumente 24\%. A evolução dos usos da água está associada ao desenvolvimento econômico e ao processo de urbanização do país. Atualmente, é consumido no Brasil um total de $1.158 \mathrm{~m} 3 / \mathrm{s}$ de água, sendo a irrigação o principal uso em termos de quantidade utilizada $(68,4 \%)$, seguida pelo abastecimento animal $(10,8 \%)$, indústria $(8,8 \%)$, abastecimento urbano $(8,6 \%)$, abastecimento rural (2,4\%), mineração $(0,8 \%)$ e termelétricas $(0,2 \%)(A N A, 2018)$.

Para Pérez (2004) há uma grande quantidade de termos que relacionam a água com seu aproveitamento como um bem, entre eles: bem comum, bem público, bem coletivo, e 
outros que se agregam à noção de patrimônio da humanidade. A diferença que se apresenta entre o bem comum e o bem público é que enquanto o bem comum é administrado pela comunidade, como auto-gestão, o bem público é administrado pelo Estado. Um elemento importante a se observar é o fato de que há grande discussão entre autores que analisam a água como um direito, como uma necessidade, e os que pensam que são ambas. A escolha de algumas dessas posturas irá direcionar os posicionamentos perante a questão da água.

Em termo de legais, o Brasil conta com a Política Nacional de Recursos Hídricos (PNRH), promulgada pela Lei Federal n 9.433/97 (BRASIL, 1997), que dispõe de uma série de objetivos, fundamentos, diretrizes gerais e instrumentos para a implantação da gestão de recursos hídricos no Brasil. Esta política também é conhecida como Lei das Águas, e tem como objetivos assegurar à atual e às futuras gerações disponibilidade de água em quantidade e qualidade necessárias, promover a utilização racional e integrada dos recursos hídricos e a prevenção e defesa contra eventos hidrológicos críticos de origem natural ou decorrentes do uso inadequado dos recursos naturais.

Essa utilização racional diz respeito as mais diversas atividades antrópicas. Pensar o uso da água significa identificar a oferta deste recurso, e então delimitar as prioridades e formas do seu uso e aplicação, garantindo a quantidade e qualidade deste bem na "devolução à natureza", possibilitando a manutenção do seu ciclo e, consequentemente, a conservação da sua oferta.

Para Junior et al. (2013) atualmente, um dos principais desafios enfrentados pela Ciência e Tecnologia para conservação e uso racional da água no semiárido brasileiro, região onde o presente estudo foi desenvolvido, encontra-se na falta de informação da população em geral, especialmente da população mais jovem e que frequentam as mais diversas escolas de ensino básico. Informação esta que auxilia a desconstruir o que Nunes (2000) destaca que em tipologias não residenciais, um aspecto importante a ser considerado é que os usuários, por não serem responsáveis diretamente pelo pagamento da água consumida, muitas vezes não se encontram motivados para a sua conservação.

No entedimento de Ywashima et al. (2006) o uso racional de água nas edificações está diretamente relacionado com o comportamento dos usuários na realização das atividadesque envolve o emprego deste insumo. Os autores ainda apontam que mesmo o emprego de tecnologias economizadoras nos pontos de consumo, sem a devida sensibilização dos usuários, pode conduzir a resultados modestos quando comparados à situação em que os usuários possuem uma postura economizadora de água.

Nessa mesma linha segue Melo et al. (2014) que destacam as unidades escolares públicas, como um ambiente frequente do uso inadequado da água e também perdas pelas condições de conservação dos sistemas hidrossanitários. O mesmo autor ainda acrescenta que consumo de água é influenciado pelo nível de esclarecimento e conhecimento dos usuários sobre a importância da conservação dos recursos naturais, da maior ou menor disponibilidade hídrica do local, da existência ou não de sistema de medição do volume consumido, dos preços pagos pela água, entre outros aspectos de natureza sociocultural, regional e econômica.

Para Gonçalves et al. (2005) o índice de patologias dos sistemas prediais de água é significativo em edificações escolares. Essa realidade é decorrente de várias causas, entre elas, a falta de sensibilização dos usuários com relação à conservação do meio ambiente e a inexistência ou ineficiência de um sistema de manutenção. Estes fatos ressaltam a importância de se estudar essa tipologia de edificação e desenvolver programas de conservação de água específicos para este público.

Segundo Fagundes et al. (2015), "a escola, ao longo da sua história, tem sido uma alternativa possível na transformação educacional e desenvolvimento de posturas críticas frente a realidade dos discentes". No que diz respeito a esse estudo referente às questões 
ambientais relacionadas ao desperdício da água, foram realizadas intervenções que buscaram contribuir para o processo de formação do sujeito para novos valores e atitudes que harmonizem a relação sociedade - natureza. Durante a aplicação de metodologias pedagógicas de intervenção, como: palestras, vídeo, gincana da água, exposição de desenhos, construção da maquete e o concurso de fotografia, observou-se significativo envolvimento de pertença e motivação da comunidade escolar com as atividades propostas. O sentimento de pertencimento promove no sujeito o apreço ao objeto alvo desta emoção, nesse caso, a água. Tal postura promove a conservação e a preservação deste recurso natural importantíssimo na manutenção da vida no planeta.

Políticas púbicas ou ações educativas que se referem ao uso racional da água mantém seu foco no aumento da produção da água, sendo escassas aquelas voltadas para a diminuição do consumo e do desperdício. Para mudança deste contexto, ações de conscientização de que a água é um recurso finito são necessárias, e com emergência (SILVEIRA et al., 2015). Chacon-Pereira et al. (2018) corroboram com a afirmação anterior e ainda complementam que a gestão dos recursos hídricos deve educar e ajustar atividades humanas para a precaução de degradação do ecossistema e para a preservação do meio, ocorrendo por meio de ações que envolvam o governo e a sociedade.

Neste contexto de comprometimento da qualidade do recurso, Leff (2009), apresenta a Educação Ambiental, como um processo dialógico que fertiliza o real e abre as possibilidades para que se chegue a ser o que ainda não se é. Essa educação permite, preparar a sociedade para a construção de uma nova racionalidade. Não para uma cultura de desesperança ou alienação, mas para um processo de emancipação que permiti novas forma de reaproximação do mundo e de convivência com os outros. Em resumo, o debate de uma educação ambiental deve ser crítico e inovador, com o desenvolvimento sustentável, funcionando com sucesso, como estratégia de sobrevivência para a espécie humana e aos demais seres vivos.

Telles (2002) abordou, na obra, Vivências Integradas com o Meio Ambiente, que "as diretrizes metodológicas existentes em Educação Ambiental são muito diversificadas e estão muitas vezes distantes das reais necessidades das comunidades com as quais se pretende desenvolver um projeto de trabalho." Baía e Nakayama (2013), reforçam a afirmação anterior, e apontam a ludicidade como metodologia alternativa, válida para desenvolver atividades em Educação Ambiental com crianças.

Para Chaguri (2006), o lúdico é caracterizado pelo prazer e esforço espontâneo. É prazeroso porque devido a sua capacidade de absorver o indivíduo de forma intensa e total, cria um clima de entusiasmo, motivador. Carvalho et al. (2014) corrobora a fala de Neves (2009) quando o mesmo afirma que através de atividades lúdicas o aluno explora muito mais sua criatividade, melhora sua conduta no processo de ensino-aprendizagem e sua auto-estima. E são várias as possibilidades de utilização do lúdico no ensino de ciências, como: teatro, confecção de brinquedos, confecção de revista em quadrinhos, jogos, dentre outros.

A representação do espaço geográfico como ferramenta pedagógica auxilia na compreensão dos envolvidos nesta abordagem, potencializando, assim, o ensino-aprendizagem, ou seja, no processo de comunicação cartográfica, a mensagem é passada a partir de um conjunto de elementos previamente organizados na maquete. A construção desse recurso didático pelos alunos permite a compreensão do espaço que está sendo trabalhado, valorizando o conhecimento prévio dos mesmos (SILVA; MUNIZ, 2012, p. 6).

Como ressalta Nacke et al. a reprodução da realidade, a partir da maquete, permite 
compreender que:

A construção de maquetes geográficas, em classe, possibilita reconhecer, através da representação, a compreensão do espaço em que o aluno está inserido; permite integração entre professor $x$ aluno, entre prática $x$ teoria; exige conhecimento do que (conteúdo) e como (forma) devemos representar; possibilita levantar hipóteses, correlacionar fatos, entre tantas alternativas do processo pedagógico (NACKE; MARTINS, p. 10).

Ainda como estrátegia pedagógica utilizada no ensino das ciências, baseada na ludicidade, destaca-se as Gincanas, que podem ser direcionadam para o desenvolvimento crítico da comunidade escolar, fazendo-os perceber a necessidade do uso racional da água no ambiente e as atividades de sucesso que os levem ao consumo consciente.

Para Melo et al. (2013), que aplicou a gincana no ensino de Ciências em escolas da Educação Básica, no município de Limoeiro, agreste de Pernambuco:

Ficou comprovado através de interação com os docentes da escola que a aplicação de jogos e gincanas educativas pode tornar-se uma metodologia de incentivo a professores para uma mudança de paradigmas, e a ajudar inter-relacionar conhecimentos específicos, exercitando a criatividade e o senso crítico (MELO et al., 2013).

A partir disso, o uso de modelos e o desenvolvimento de atividades lúdicas podem auxiliar o professor a despertar o interesse dos alunos, tornando a aprendizagem mais significativa, por meio da visualização e interação com o recurso didático. Estimulando assim, o aluno a participar do processo, possibilitando momentos prazerosos de aprendizado (HERMANN; ARAÚJO, 2013; BEZERRA e SOUZA 2021). Sendo assim, esse trabalho se propôs promover intervenções lúdicas, integradas com toda a comunidade escolar, para ampliar a percepção acerca do uso racional da água, no ambiente escolar.

\section{Desenvolvimento}

A pesquisa se desenvolveu em uma instituição pública, localizada no bairro Jardim Acácia, município de Feira de Santana, Bahia. O CEGME (Colégio Estadual Georgina de Mello Erismann) possui uma equipe funcional de 27 profissionais da educação: 22 professores efetivos e 5 estagiários, 01 diretor, 02 vice-diretores, 01 secretária, 01 articuladora de área, 19 funcionários (administrativos, terceirizados e vigilantes) e 363 discentes; contabilizando, assim, um total de 414 pessoas fazendo parte dessa comunidade escolar. No turno integral, manhã e tarde, estudam 187 discentes, sendo que uma grande parcela destes estudantes está matriculada no ensino fundamental, 74,3\%; enquanto no turno noturno, o inverso ocorre: dos 176 estudantes, a maior parcela destinase ao ensino médio, 61,9\%. O prédio escolar, estrutura física, consta de 8 salas de aula, diretoria, secretaria, sala de professores, uma sala de informática com 18 computadores conectados à internet e banda larga, cozinha, quadra poliesportiva, biblioteca, sala polivalente, sala multimídia e uma sala do grêmio estudantil, estacionamento privativo para funcionários e professores e uma grande área externa. Em termos de infraestrutura sanitária, existem quatro banheiros sendo um para os docentes e a gestão, um para os funcionários e os outros dois para os discentes, sendo um feminino e o outro masculino. Os banheiros dos funcionários e os dos estudantes possuem chuveiros.

O estabelecimento de ensino situa-se no semiárido baiano em que o uso adequado da água é uma questão de sobrevivência, de acordo com Santos et al. (2013, p. 263): 
No Brasil termos como "indústria da seca" e "polígono das secas" são constantemente relacionados à região semiárida do país. Além dos fatores climáticos, atribui-se isto a questões políticas e de infraestrutura, sendo consenso que a principal forma de convivência com a escassez de água é o seu uso racional (grifos do autor).

O grupo participante, ensino integral, da pesquisa foi formado por 229 pessoas, composto por discentes, docentes, gestores, coordenadores pedagógicos, funcionários e vigilante, que, de maneira espontânea, aderiram à proposta.

A primeira etapa foi a avaliação diagnóstica, com toda a comunidade escolar. Os dados foram obtidos mediante observação das atividades do estabelecimento com interface ao uso da água através de formulários de observação, aplicação de questionários com perguntas dicotômicas e de múltipla escolha. A segunda etapa foram as intervenções artísticas a partir da realização da feira de ciências, e da gincana da água. A terceira, e última etapa foi a nova avaliação diagnóstica, pós-intervenção.

Dos 229 participantes da presente pesquisa observa-se que, 75\% eram discentes, 13\% docentes, 12\% funcionários (secretaria, limpeza, vigilância), e 1\% são gestores. Destaca-se com esses dados a grande adesão dos discentes a proposta do trabalho, e o envolvimento dos funcionários, na proposta, o que não é comum, em trabalhos de educação ambiental, em ambiente escolar.

A Feira de Ciência foi um evento que envolveu toda a comunidade escolar, onde cada ano escolar apresentou um produto artístico, desde desenhos (Figura 1), fotografias, palestras e maquetes (Figura 2). Já a gincana da água, contou com provas (torta na caraperguntas sobre o uso racional da água, cano furado- vence quem conseguir atravessar a área conservando a maior quantidade de água possível, bexiga d'água- arremesso da bexiga, sem deixá-la cair), cordéis, arrecadação de garrafas plásticas para descarte adequado, produção de peça teatral.

Figura 1 - Desenho produzido por alunas do $6^{\circ}$ e $8^{\circ}$ ano do ensino fundamental do Colégio Estadual Georgina de Mello Erismann, Feira de Santana-BA, durante a Feira de Ciências.
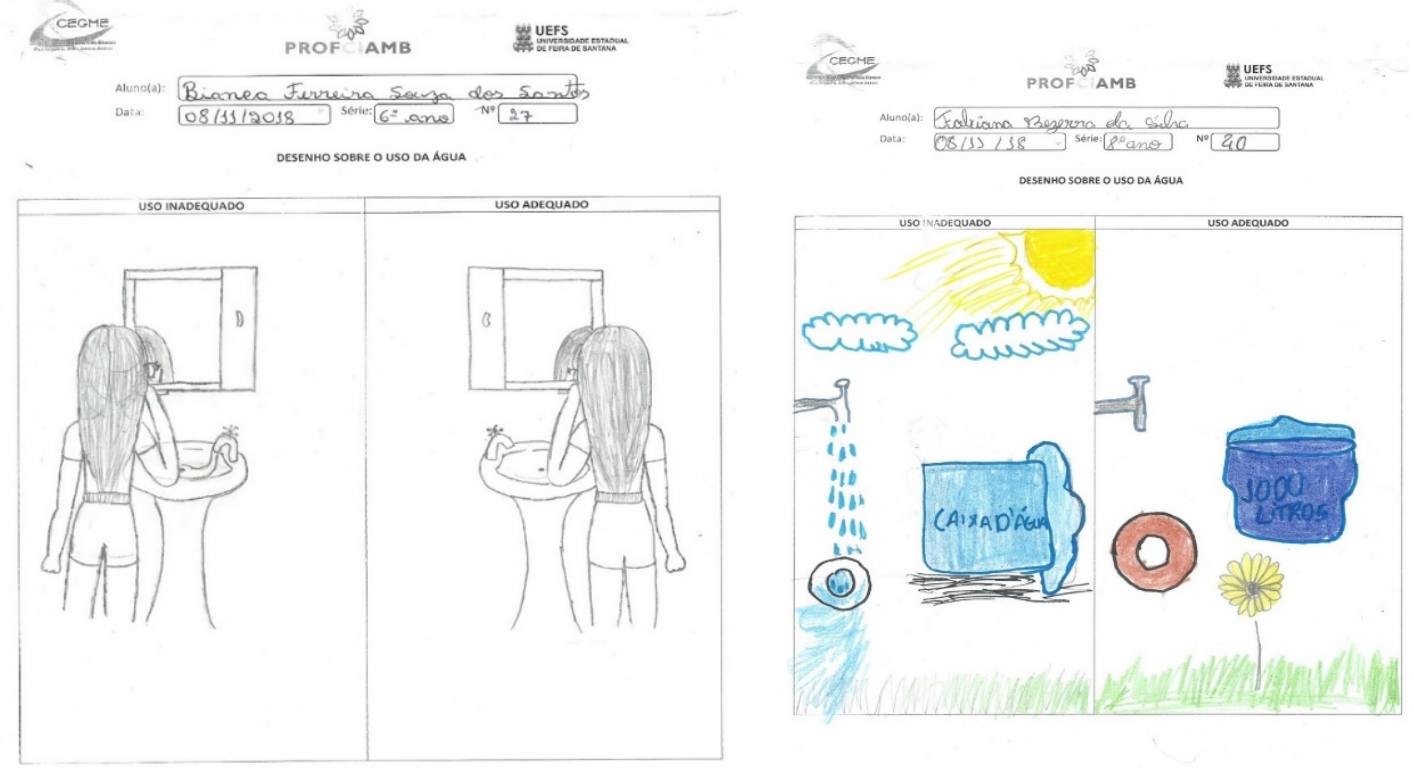
A exposição de desenhos foi realizada pelos estudantes do ensino fundamental, totalizando, assim, 84 (oitenta e quatro) produções artísticas. Os participantes tiveram a oportunidade de registrar o seu entendimento sobre o uso da água, posturas inadequadas e adequadas em um quadro comparativo. Para Rezler et al. (2009), os desenhos têm suas particularidades. Uma análise individual pode ser realizada, salientando características que chamam a atenção. Assim, pode-se refletir e utilizar para discussões com os estudantes uma série de considerações sobre o meio ambiente preservado ou não, natural ou construído, a presença do homem e sua interação com o ambiente, as medidas preventivas e as soluções possíveis para os problemas causados.

$\mathrm{Em}$ ambas as evidências coletadas (desenhos e fotorgafias), percebeu-se a consciência da existência ou ocasionalmente do dano ambiental, estando intimamente relacionado à responsabilidade civil (ou falta de), enquanto prejuíz causado a um recurso ambiental natural indispensável para um ambiente equilibrado ecologicamente - o que possibilita espaço para a ação da Educação Ambiental.

Figura 2 - Apresentação da maquete pelos estudantes do $1^{\circ}$ e do $2^{\circ}$ ano do ensino médio, Colégio Estadual Georgina de Mello Erismann, localizado no Bairro Jardim Acácia, Feira de Santana-BA.

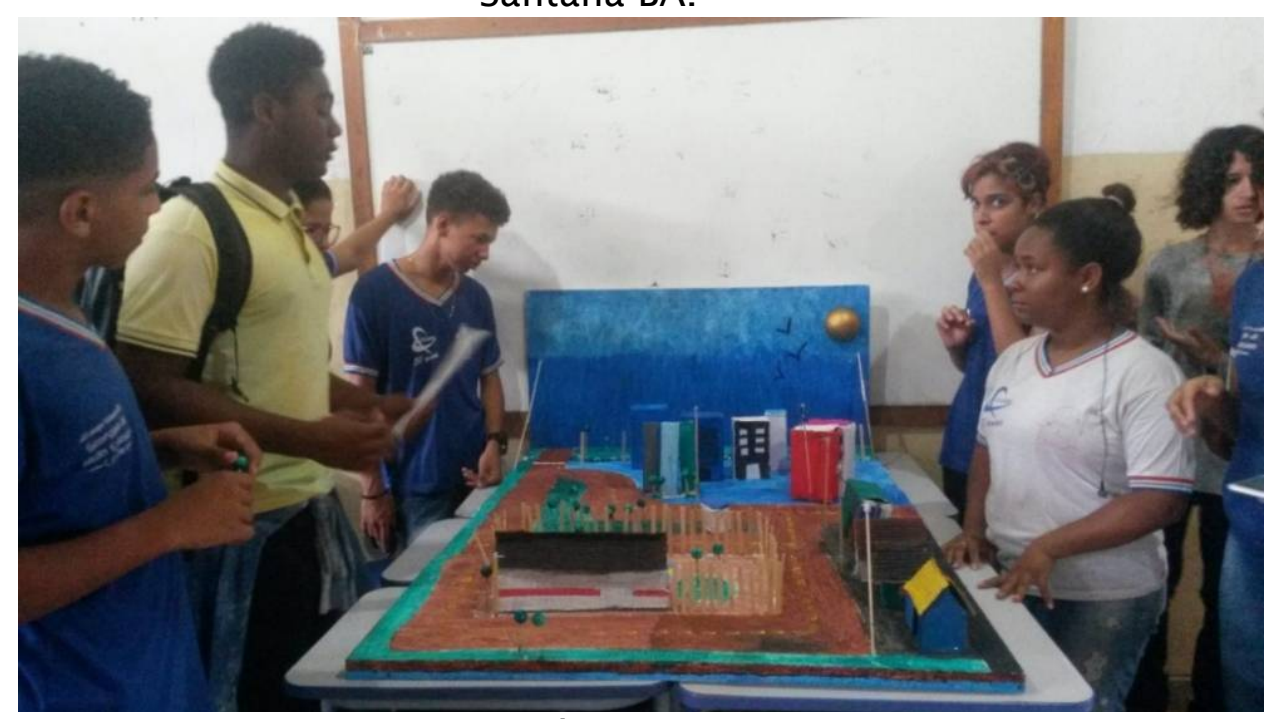

Fonte: Próprio autor, 2019.

Sobre a maquete, sua representatividade e o envolvimento dos estudantes na atividade desenvolvida, é conveniente mencionar o depoimento 01 , a seguir, como uma percepção do trabalho executado.

01. [...] então eles conseguiram colocar ali os conceitos de bacia hidrográfica que foi trabalhado, os conceitos de consumismo, conseguiram explicitar de forma lúdica os conhecimentos sobre $o$ ciclo da água, sobre interferência humana, exposição do lixo. Essa parte de avaliar todo um processo ficou muito claro nessa culminância que foi a produção da maquete (Iraneia Leite, professora de Química e vice-diretora do turno noturno, Informação verbal).

De acordo com Pereira et al. (2000) e corroborado por Moura et al. (2020), gincanas e feiras de Ciência propiciam um conjunto de experiências capazes de estimula a atividade científica e a elaboração de soluções aos problemas da atualidade.

Gonçalves (2008) ressalta que as Feiras sejam a culminação de um trabalho escolar, e 
não a realização de uma atividade extemporânea, realizada apenas para que um evento dessa natureza aconteça na escola. O presente trabalho se preocupou com o que foi apontado pelo autor, e assim fez da Feira o evento de encerramento, antecedido pelas sessões de palestras, vídeos e cursos, que embasaram as intervenções artísticas.

Ainda como parte da da formação teórica para embasar as intervenções artísticas, os estudantes do terceiro ano do ensino médio passaram podr um curso, com a temática "Uso racional da água", tendo como base teórica, os cursos de capacitação da ANA (Agência Nacional de Águas), disponível no endereço: http://capacitacao.ana.gov.br. Estudantes do terceiro ano foi definido por se tratar do último nível de escolaridade oferecido pela instituição, o que atribiu a eles habilidades, competências e maturidade acadêmica, para compreender e multiplicar o conhecimento proposto para a comunidade escolar. Além dos estudantes do terceiro ano, professores, estudantes, gestores e funcionários também participaram, totalizando 93 (noventa e três) membros da comunidade escolar capacitados. Para avaliar o curso, foi aplicado um questionário que indagou os participantes quanto ao material didático usado como referencial teórico. No total, 86 (oitenta e seis) participantes opinaram, avaliando como "ÓTIMO" 60,47\%, "BOM" em 37,21\%, "REGULAR" em 2,33\%, e não houve classificação considerada "RUIM".

Freitas e Marin (2015), avaliando a abordagem da educação ambiental nas escolas municipais da cidade de Presidente Prudente (SP), conclui que todos os docentes tratam o livro didático como principal material para suas aulas. Porém, os autores pontuam que seu uso requer cuidados. É imprescindível oferecer aos alunos situações que Ihes permitam pesquisar, contextualizar os conhecimentos. Os professores têm a tarefa de aprofundar os saberes, evitar a fragmentação dos conhecimentos, complementar as lacunas e superar as fragilidades desses materiais. Sendo assim este estudo se preocupou em trazer as produções artísticas, o que possibilitou não apenas trabalhar o intelecto dos estudantes, mas trouxe a realidade para a sala de aula.

O processo ensino - aprendizagem por meio das manifestações artísticas potencializa a aquisição do conhecimento acadêmico (LIMA, 2018). Na educação Waldorf, a arte é um instrumento mediador no processo ensino e aprendizagem, um facilitador na articulação dos mesmos. Ainda com base na metodologia da educação Waldorf, os resultados provenientes da aplicação de atividades artísticas não se resumem à obra de arte, e sim, na busca do aperfeiçoamento das aptidões, no desejo de unir arte e ciências simultaneamente.

O estímulo para trabalhar esse tema de uma maneira interdisciplinar tende a potencializar a aquisição do conhecimento por parte dos alunos, e também, da comunidade escolar. Jacob (2003) menciona sobre a perspectiva da interdisciplinaridade, como aporte para fortalecer os diversos sistemas de conhecimento, capacitação de professores e toda a comunidade acadêmica, sobretudo nas questões ambientais. $O$ presente estudo questionou os estudantes em relação as disciplinas que abordavam a temática, e obteve os seguintes resultados: Ciências com 68,94\%; Educação Científica, 49,24 \%; Geografia, com um percentual de 29,55\%; e, Química, com 28,03\%. A água como tema transversal deveria ser abordado por todas as disciplinas do ensino fundamental e médio, e acredita-se que o total envolvimento dos professores de outras discilinas, a exceção de ciências, foram as intervenções artísticas. A Figura 3, apresenta o professor de geografia fazendo uma palestra sobre as Bacias Hidrográficas. 
Figura 3 - Palestra sobre bacia hidrográfica e ciclo da água realizada pelo professor de Geografia para os estudantes do ensino médio no Colégio Estadual Georgina de Mello Erismann, localizado no Bairro Jardim Acácia, Feira de Santana-BA.

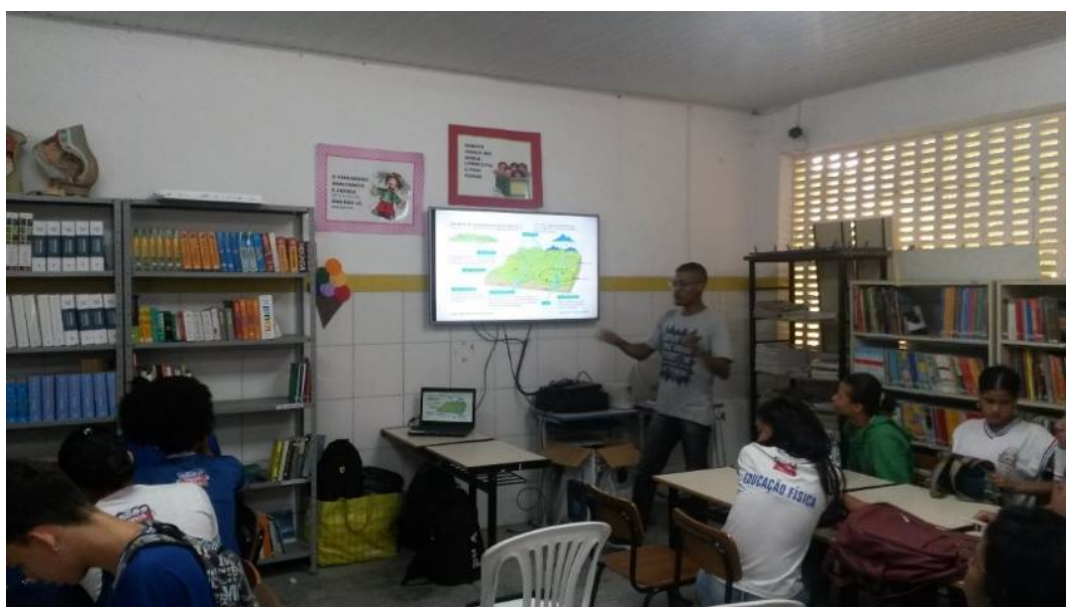

Fonte: Próprio autor, 2019.

A construção da maquete representou o substrato em que se desenvolveu o processo de produção dos conhecimentos sobre as características que abrangem o ciclo da água, o uso deste recurso no ambiente escolar e do processo de ensino-aprendizagem. A maquete facilitou a visualização do ambiente, pois serviu como ponto de referência para a organização das atividades seguintes, inclusive ações para a melhoria do uso da água na comunidade escolar.

De acordo com Altman e Chemers (1989), um dos primeiros processos da percepção ambiental é a obtenção de informações sobre o ambiente. Para Zanatta (2013) é de grande importância trabalhar com a educação ambiental nas escolas, já que estas são o espaço social e o local onde o aluno dará sequência ao seu processo de socialização. O que nela se faz, se diz e se valoriza, representa um exemplo daquilo que a sociedade deseja e aprova. Comportamentos ambientalmente corretos devem ser aprendidos na prática, no cotidiano da vida escolar, contribuindo para a formação de cidadãos responsáveis.

A fase de diagnóstico, realizada antes e depois das intervenções artísticas foram imprescindíveis para avaliar a eficiência da abordagem.

Ao questionar a comunidade acerca do incômodo com os problemas ambientais do ambiente escolar, observa-se que o incômodo se mantém, antes e depois da intervenção artística, porém, com a intervenção a porcentagem de percepções a respeito de como a comunidade desperdiça a água, vai de 9\% (antes da intervenção), para, aproximadamente, 33\% (após a intervenção) (Figura 4). 
Figura 4 - Resultados apresentados, em percentagem, quando questionados sobre a preocupação a respeito dos problemas ambientais no Colégio Estadual Georgina de Mello Erismann, Feira de Santana-BA.

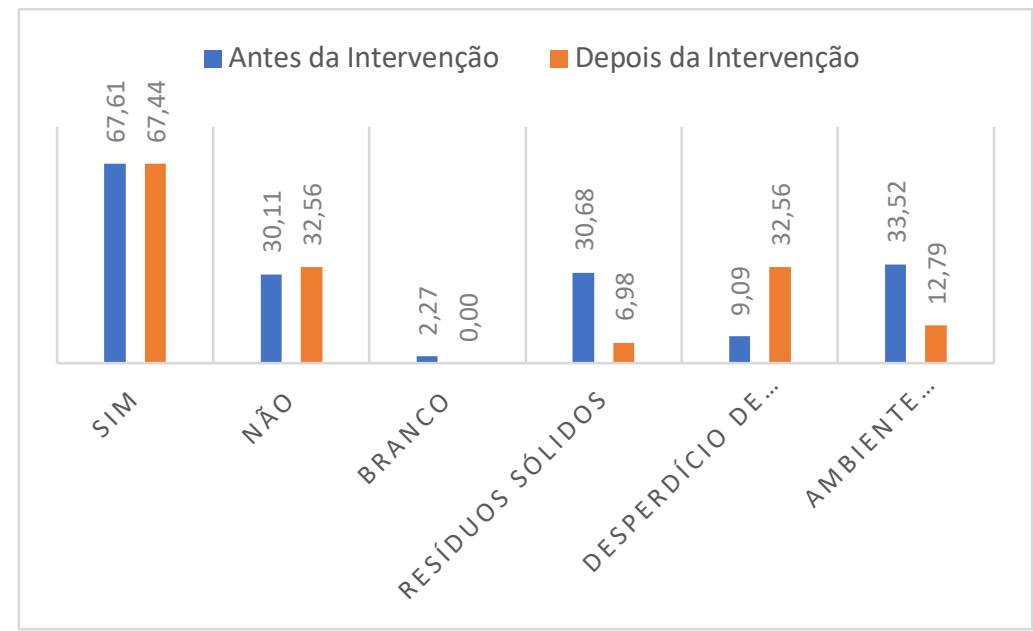

Fonte: Autoria própria, 2019

Como formas de compreender os possíveis ambientes onde o desperdício pudesse ser apontado, a comunidade foi questionada sobre os ambientes que mais utilizam a água (Figura 5).

A comunidade escolar aponta maior consumo de água na limpeza dos banheiros, seguidos pela limpeza do piso, preparo e cozimento dos alimentos respectivamente e, por fim, rega de plantas. Vale ressaltar que a limpeza dos banheiros acontece diariamente e sob a vista de todos os que convivem e frequentam o colégio.

Figura 5 - Resposta da comunidade do Colégio Estadual Georgina de Mello Erismann, localizado no Bairro Jardim Acácia, Feira de Santana-BA, em relação à pergunta: Na sua opinião qual atividade mais consome água no colégio?

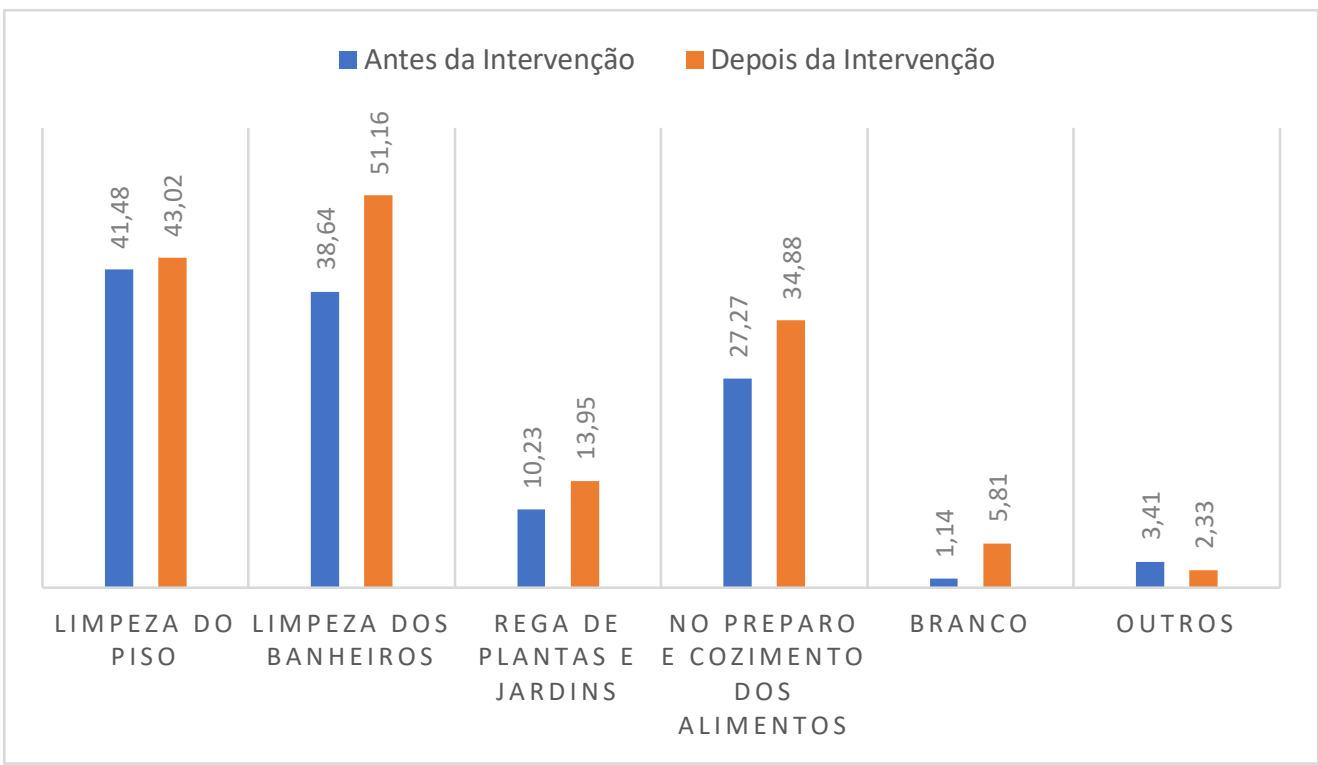


Fonte: Autoria própria, 2019.

Melo et al. (2014), analisaram o consumo de água em escolas públicas do Triângulo Mineiro, e observaram que, em relação à limpeza do ambiente escolar, a utilização do balde prevalece sobre o uso da mangueira na limpeza do piso e louças sanitárias nos banheiros, cozinhas e área interna, com lavagens diárias dos banheiros e cozinhas. Já na área externa, a utilização de mangueira é predominante. Soares et al. (2017) analisaram o consumo de água de duas escolas públicas da cidade de Recife (PE), e observaram que o setor de expressão no consumo mensal da água nas duas escolas foi diferente: na escola A foi a copa (41\%), e na escola B foi a área comum (37\%), como o presente estudo. Soares justifica que a frequência de limpeza na escola $A$ é menor que na $B$, por isso consome menos água. Nas duas instituições eram preparados três lanches e um almoço, todos os dias.

Para Melo et al. (2014) as formas como as atividades consumidoras de água são executadas interferem no gasto deste recurso em qualquer espaço da sociedade. Isto, no caso dos setores consumidores de água nas escolas, especificamente, inclui os modos como a água é empregada na limpeza e manutenção dos ambientes, os tipos de aparelhos hidrosanitários e os hábitos dos usuários. Por isso, apresentamos ao público escolar o questionamento referente às atividades que, na visão deles, mais consumia água no ambiente escolar.

O desperdício, colocado em evidência após a intervenção artística, foi retratado a partir da observação de equipamentos danificados (37\%), em relação a hábitos inadequados (13\%), os demais não opinaram. Melo et al. (2014) puderam observar que, na percepção dos usuários, existe acentuada falta de preocupação com o uso adequado dos equipamentos hidrossanitários, com poucos usuários que associaram o consumo inadequado a uma possível quebra do equipamento. Os agentes de serviços gerais entrevistados mostraram-se conhecedores das tecnologias atuais sobre equipamentos hidrossanitários que utilizam uma quantidade menor de água, em relação aos tradicionais. Todavia, existe a preocupação com relação ao uso correto, por parte dos alunos, associado aos possíveis atos de vandalismo.

Foi significativa a escolha da educação ambiental como solução para redução do consumo de água no colégio, principalmente pelo grupo que não sabia informar, antes da intervenção (Figura 6). 
Figura 6 - Resposta da comunidade do Colégio Estadual Georgina de Mello

Erismann, localizado no Bairro Jardim Acácia, Feira de Santana-BA, em relação à pergunta: Para você, qual a melhor maneira de reduzir o consumo de água no seu colégio?

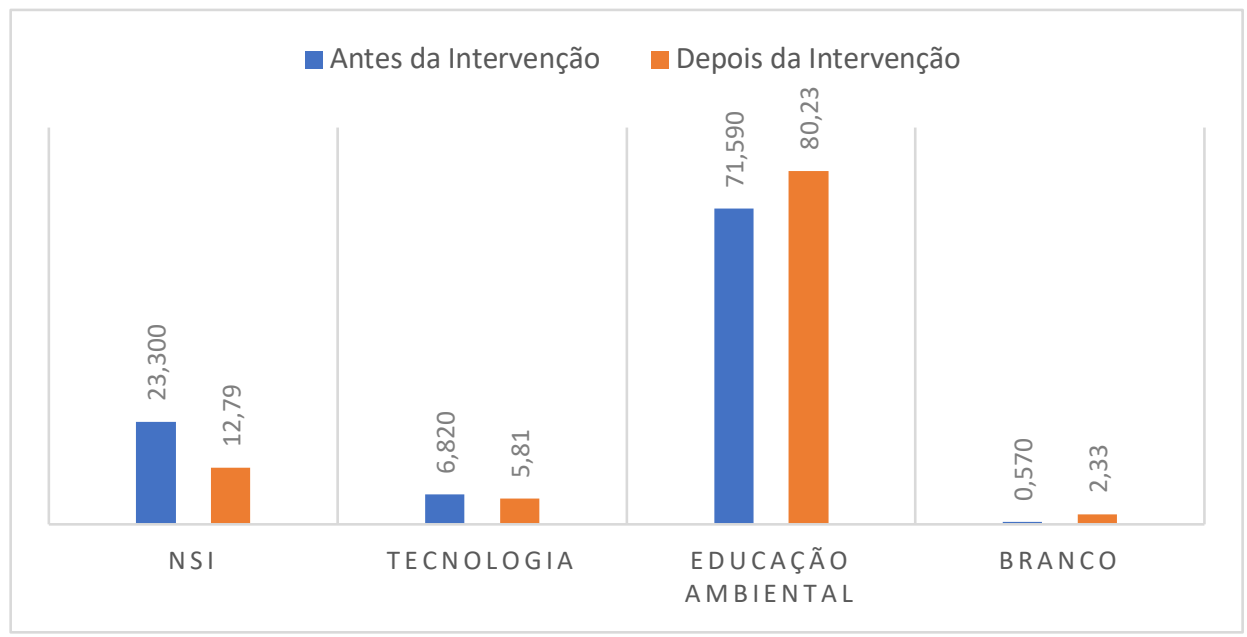

Fonte: Autoria própria, 2019.

Assim como Oliveira (2013), este trabalho constatou que o usuário do ambiente escolar tem o conhecimento de atitudes a serem empregadas para economizar este insumo, porém, o que falta é a prática, ou seja, a transformação destas atitudes em ações concretas e efetivas, de forma que os recursos hídricos sejam utilizados racionalmente (Figura 7). Este mesmo autor indica as atividades lúdicas como importantes para os usuários adotarem as novas práticas de consumo consciente. Com base nessa conclusão, foram adotadas ações para estimular esta prática, e uma delas foi a representação ilustrativa do uso da água no ambiente escolar.

Figura 7 - Resposta da comunidade do Colégio Estadual Georgina de Mello Erismann, localizado no Bairro Jardim Acácia, Feira de Santana-BA, em relação a pergunta: Qual(ais) atividade(s) que sugere para reduzir o consumo de água no seu colégio?

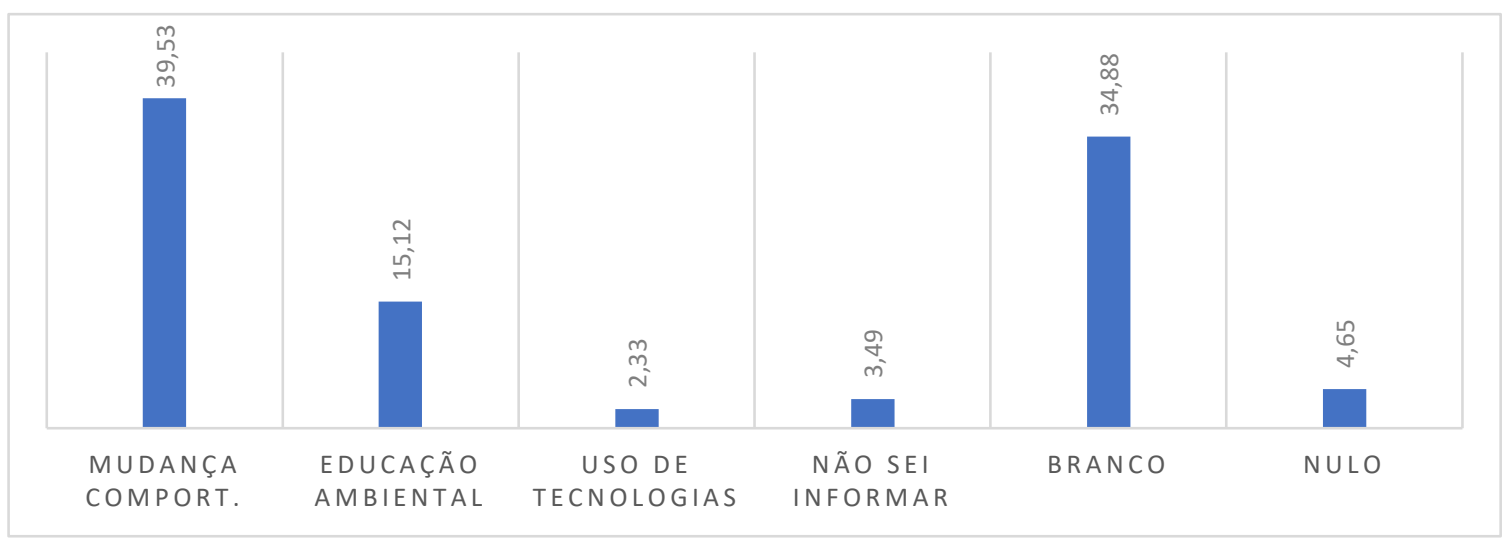

Fonte: Autoria própria, 2019. 
Ywashima (2005) e Nunes et al. (2018) evidenciam que em muitos casos, a redução de consumo não depende apenas da instalação e da eficiência dos equipamentos com tecnologia economizadora, mas também do comportamento dos usuários. Sendo assim, a academia tem um importante papel a desempenhar nesse tema, seja através da pesquisa de novas tecnologias, do desenvolvimento de Programas do Uso Racional da Água ou da participação na conscientização da sociedade para o papel de cada cidadão na conservação da água. Oliveira (1999), corroborado por Silva (2016) também acompanham o que foi descrito anteriormente e destacam três possibilidades de ação: econômicas, sociais e tecnológicas. As ações econômicas compreendem incentivos e desincentivos econômicos, como o aumento de tarifas ou subsídios para aquisição de equipamentos economizadores. As ações sociais caracterizam campanhas educativas para conscientização dos usuários. As ações tecnológicas, consideradas de maior impacto, constituem em implantação de sistemas de medição setorizada do consumo de água, substituição de equipamentos, e detecção e correção de vazamentos. Ou seja, para ter um efetivo consumo consciente, faz- se necessário a associação entre as ações.

Ao término da pesquisa, após as atividades lúdicas e encerramento do pósdiagnóstico, foi realizado um acompanhamento na rotina dos funcionários da escola, fazendo o possível para que os mesmos não notasem, e foi possível verificar vários procedimentos adequados ao uso racional da água, a saber: limpeza do piso com pano molhado e balde; as torneiras completamente fechadas durante a preparação dos alimentos, ao ensaboar os utensílios, e no processo de descongelamento da carne.

Por fim, avaliando as médias de consumo de água nos anos de 2018 (antes da intervenção) e em 2019 (ano da intervenção), observa-se uma redução de 3.000 (três mil) litros de água por mês, acredita-se que seja o resultado inicial, as intervenções realizadas, reforçando que as ações findaram em junho de 2019, o que reflete em, pelo menos 6 meses, de construção de novas percepções (Figura 8).

Figura 8 - Média do consumo de água $\left(\mathrm{m}^{3}\right)$ no Colégio Estadual Georgina de Mello Erismann, localizado no Bairro Jardim Acácia, Feira de Santana-BA, dos anos de 2018 e 2019.

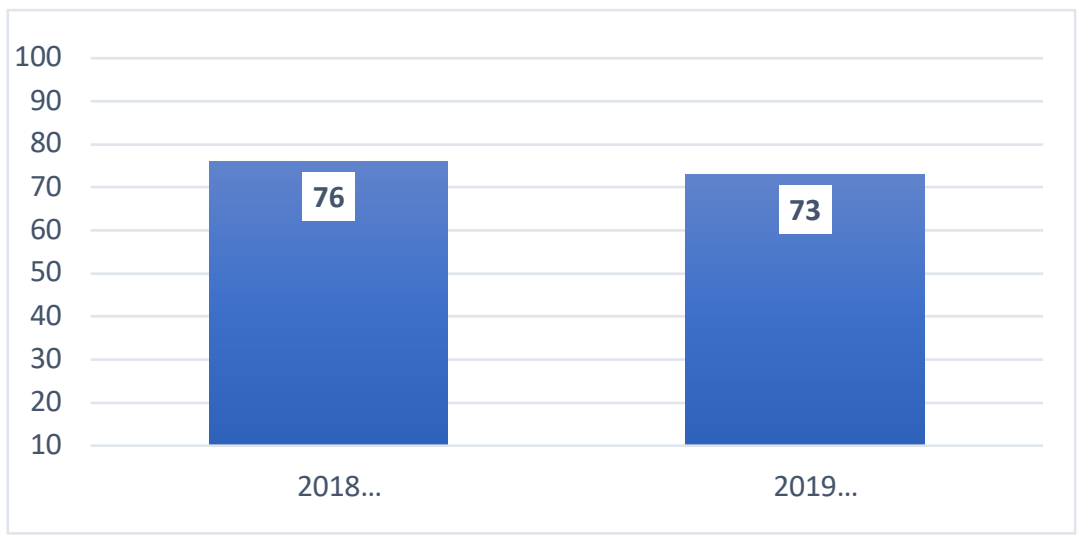

Fonte: EMBASA, $2018 / 2019$.

\section{Conclusão}

Os dados obtidos nesta pesquisa foram um importante ponto de partida para novas 
discussões no que diz respeito a projetos de Educação Ambiental nas escolas, bem como na ampliação do olhar para outros espaços educativos, como forma de maior interação e aproximação homem/natureza; necessidade de ações periódicas e constantes de educação continuada no ambiente escolar; e a relevância da abordagem e do desenvolvimento do tema nas instituições de ensino. Estimular as reflexões coletivas sob 0 uso de representações da realidade através de produções estudantis, com orientações e participações de diversos professores das diversas áreas do conhecimento.

As intervenções artísticas alertaram para a importância na formação crítica, reflexão, diálogos e à ampliação das percepções de todos os envolvidos. A construção sob o olhar interdisciplinar agregou valores para uma visão sistêmica do problema, o uso inadequado da água.

Este trabalho utilizou ferramentas pedagógicas propostas para como alternativas possíveis para tornar o fenômeno educativo mais pertinente à realidade prática, entendendo que, através das atividades de produção artísticas e culturais, a comunidade escolar teve a oportunidade de vivenciar o processo de educação ambiental, sobretudo no que se refere à água, sendo agente ativo no processo ensino-aprendizagem.

Espera-se que este levantamento de dados indicados na pesquisa, venha a contribuir para o pensar sobre as questões ambientais, sobretudo sobre o uso racional da água e possibilite a construção de alguns referenciais que auxiliem os docentes e gestores na elaboração de novos projetos.

\section{Agradecimentos}

A toda a comunidade escolar do Colégio Estadual Georgina Erisman, e ao Programa do Mestrado profissional em Rede para ensino das Ciências Ambientais.

\section{Referências}

ALTMAN, I.; CHEMERS, M. Culture and Environment. New York, Cambridge: Cambridge University Press, 1984.

ANA. Agência Nacional de Águas. Conjuntura dos recursos hídricos no Brasil 2018. Brasília: ANA, 72 p. 2018.

BEZERRA, L. A.; SOUZA, L. C. A. Desenvolvimento de uma Ecosfera: Um Recurso Didático para o Ensino da Educação Ambiental e Sustentabilidade. Educação Ambiental em Ação, ISSN 1678-0701, Volume XIX, Número 74, Março-Maio/2021.

BRAGA, Benedito et al. Introdução à engenharia ambiental. São Paulo: Prentice Hall, 2002.

BRAISL, Ministério do Meio Ambiente dos Recursos Hídricos e da Amazônia Legal. Lei n. 9.433: Política Nacional de Recursos Hídricos. Brasília: Secretaria de Recursos Hídricos, 72 p. 1997.

CARVALHO. P. S. de; ARAÚJO, W. A. De.; ARAÚJO, E. S. A. A LUDICIDADE: IMPORTANTE FERRAMENTA METODOLÓGICA PARA O ENSINO DE CIÊNCIAS. Anais Educon, Aracaju, Volume 08, n. 01, ISSN: 1982- 3657. p.1-7, set/2014. Disponível em:

<https://educonse.com.br/viiixcoloquio>. Acessado em: 11 mai. 2021.

CHACON-PEREIRA, A.; BATALHÃO, A. C. S.; SILVA, L. P.; NEFFA, E. Educação Ambiental na gestão de recursos hídricos baseada no modelo de licenciamento ambiental.

Desenvolv. Meio Ambiente, v. 49, n.1, p. 36-59, dez. 2018.

CHAGURI, J. P. O uso de atividades lúdicas no processo de ensino/aprendizagem de espanhol como língua estrangeira para aprendizes brasileiros. Revista X, v. 2, 2009. 
Disponíve em:

<http://www.educadores.diaadia.pr.gov.br/arquivos/File/2010/artigos_teses/LinguaEspan hola/artigos/4Chaguri.pdf>. Acessado em: 12 mai. 2021.

COSTA, M. C. R.; RODRIGUES, M. R. A. S.; MENDES, F. R. S.; VASCONCELOS, S. O. S.; MEDEIROS, N. F. M.; MARINHO, M. M.; MARINHO, E. S. Contextualização do uso racional da água pelas escolas públicas de Limoeiro do Norte (Ceará - Brasil): Experiência formativa na Extensão Universitária. Revista Brasileira de Meio Ambiente, v.8, n.1. 030-042. 2020.

FREITAS, N. T. A.; MARIN, F. A. D. G. Educação ambiental e água: concepções e práticas educativas em escolas municipais. Revista Nuances: Estudos sobre educação. UNESP. v. 26. 2015.

GONÇALVES, O.; ILHA, M.; AMORIM, S.; PEDROSO, L. Indicadores de uso racional de água para escolas de ensino fundamental e médio. Ambiente Construído, Porto Alegre, v.5, n.3, p.35-48, jul/set, 2005.

GONÇALVES, T. V. O. Feiras de ciências e formação de professores. In: PAVÃO, A. C.; FREITAS, D. Quanta ciência há no ensino de ciências. São Carlos: EduFSCar, 2008.

JACOBI, Pedro. Educação ambiental, cidadania e sustentabilidade. Cadernos de Pesquisa, n. 118 , p. 189-205, março/ 2003.

JUNIOR, J. A. M. S.; JUNIOR. G. B.; SANTOS, J. K. L.; BRITO. E. T. F. S. Uso racional da água: ações interdisciplinares em escola rural do semiárido brasileiro. Ambi-Agua, Taubaté, v. 8, n. 1, p. 263-271, 2013. Disponível em:

$<$ https://www.scielo.br/scielo.php?pid=S1980993X2013000100019\&script=sci_arttext\&tln $\mathrm{g}=\mathrm{pt}>$. Acessado em: 12 mai. 2021.

LEFF, E. Complexidade, racionalidade ambiental e diálogo de saberes. Educação \& Realidade. v. 34, p.17-24, 2009.

LIMA, C. B. de. Pedagogia waldorf: a arte como mediação no processo de ensinoaprendizagem. V CONEDU, Congresso Nacional Educação. Anais. Universidade Federal do Paraná, 2018.

LIMA, G. F. da C. O debate da sustentabilidade na sociedade insustentável. Revista Política \& Trabalho, n 13: 201-222, João Pessoa: PPGS/UFPB, setembro/1997.

MASSINE, M. C. L. Sustentabilidade e educação ambiental: considerações acerca da política nacional de educação ambiental - a conscientização ecológica em foco. In: Encontro Nacional do Conpedi, Fortaleza, 2757-2769 pp. 2010.

MELO, N. A.; SALLA, M. R.; OLIVEIRA, F. R. G.; FRASSON, V. M. Consumo de água e percepções dos usuários sobre o uso racional de água em escolas estaduais do Triângulo Mineiro. Ciência \& Engenharia (Science \& Engineering Journal), v. 23, n. 2, p. 01-09, jul.dez. 2014.

MELO. T. L. R. de; SILVA. G. G. da.; SILVA. B. W. da C.; MELO. M. da C. C. ENSINO DE CIÊNCIAS ATRAVÉS DE GINCANAS EDUCATIVAS: Uma proposta de ludicidade. Anais I CONAPESC. Disponível em: <http://www.editorarealize.com.br>. Acessado em: 12 mai. de 2021.

MOURA, E. P. de; OLIVEIRA, L. A. T.; NUNES, M. M; SANTOS, M. do S. L.; OLIVEIRA, S. M. L. Dia Mundial da Água: a gincana como ferramenta de ensino e sensibilização. Braz. J. of Develop., Curitiba, v. 6, n.12, p.101638-101645 dec. 2020.

NACKE, Sonia Mary Manfroi; MARTINS, Gilberto. A maquete cartográfica como recurso pedagógico no ensino médio. Disponível em: <http://www.gestaoescolar. 
diaadia.pr.gov.br/arquivos/File/producoes_pde/artigo_sonia_mary_manfroi_nacke.pdf> . Acesso em:16 mai. 2020.

NUNES, L. G. C. F. Plano de conservação de água: escolas públicas estaduais da cidade do Recife. Dissertação de Mestrado. 154f. Escola Politécnica da Universidade de Pernambuco. Recife, PE. 2018.

NUNES, S. da S. Estudo da conservação de água em edifícios localizados no Campus da Universidade Estadual de Campinas. Dissertação de Mestrado em Engenharia Civil. Universidade Estadual de Campinas. Campinas, SP. 2000.

OLIVEIRA, F. R. G. Consumo de água e percepção dos usuários para o uso racional de água em escolas estaduais de Minas Gerais. 2013. 193 fl. Dissertação de Mestrado. Programa de Pós-Graduação em Engenharia Civil. Faculdade de Engenharia Civil, Universidade Federal de Uberlândia, 2013.

OLIVEIRA, L. H.; GONÇALVES, O. M. Metodologia para a implantação de programa de uso racional de água em edifícios. Boletim Técnico da EPUSP. Universidade de São Paulo. São Paulo, 1999.

PEREIRA, A. B.; OAIGEN, E. R.; HENNING G. Feiras de Ciência. Canoas: Ulbra, 2000.

PÉREZ, J. E. C. A gestão de água no Vale de Quíbor: uma análise psicossocial de uma forma tradicional de manejo de um bem comum. Doutorado em Psicologia Social. Pontifícia Universidade Católica de São Paulo. São Paulo, 2004.

REZLER. M. A.; SALVIATO, G. M. S. WOSIACKI, S. R. Quando a imagem se torna linguagem de comunicação de estudantes da $5^{\mathrm{a}}$ e $6^{\mathrm{a}}$ séries do ensino fundamental em Educação Ambiental. Revista Electrónica de Enseñanza de las Ciencias, vol.8, nº.304. 2009. Disponível em:

$<$ http://reec.educacioneditora.net/volumenes/volumen8/ART16_Vol8_N1.pdf $>$. Acessado em: 10 mai. 2021.

SANTOS JÚNIOR, J. A.; BARROS JÚNIOR, G.; SANTOS, J. K. L.; BRITO, E. T. F. S. Uso racional da água: ações interdisciplinares em escola rural do semiárido brasileiro. Ambi-água, Taubaté, v. 8, n. 1, p. 263-271, 2013.

SILVA, J. M. O. F. da; SILVA, R. O. F.; OLIVEIRA, J. R.; BARBOSA, R. C. Cordel como instrumento pedagógico para educação ambiental. Revista Acadêmica Científica SciRe; ISNN 2317.661x; Vol. 08. Num. 02. Agosto, 2015.

SILVA, V.; MUNIZ, A. M. V. A geografia escolar e os recursos didáticos: o uso das maquetes no ensino-aprendizagem da geografia. Geosaberes: Revista de Estudos Geoeducacionais; Vol. 03, n. 5, p. 62-68, jan/ jun. 2012.

Silva. S. R. da. Consumo de água em escolas públicas: uma referência para o município do Recife. Dissertação de Mestrado em Engenharia Civil. Recife: UPE, Escola Politécnica, 66 f. 2016.

SILVEIRA, A. P. G.; LIMA MELO, B.; OLIVEIRA MENDES, T.; BEZERRA, H. R. S.; RAMOS, G. C.; REIS, J. S.; SILVA, P. S. F. Educação Ambientale consumo consciente da água. Anaisdo $55^{\circ}$ Congresso da Associação Brasileira de Química, Goiânia, nov. 2015. Disponível em:

<http://www.abq.org.br/cbq/2015/trabalhos/5/8210-21535.html>. Acessado em: 10 mai. 2021.

SOARES A. E. P. et al. Diagnóstico dos Indicadores de Consumo de Água em Escolas Públicas de Recife-PE. Periódico eletrônico Fórum Ambiental de Alta Paulista, v. 13. n. 1. 2017. 
YWASHIMA, L. Avaliação do uso da água em edifícios escolares públicos e análise de viabilidade econômica da instalação de tecnologias economizadoras nos pontos de consumo. Dissertação de Mestrado em Engenharia Civil. Universidade Estatual de Campinas. Campinas, SP, 2005.

YWASHIMA, L.; ILHA, M.; CRAVEIRO, S.; GONÇALVES, O. Método para Avaliação da Percepção dos Usuários para o Uso Racional de Água em Escolas. In: CONFERÊNCIA LATINO-AMERICANA DE CONSTRUÇÃO SUSTENTÁVEL, 1.; Anais do Encontro Nacional de Tecnologia do Ambiente Construído, 11. São Paulo: Entac, 2006.

ZANATTA, T.; ROSA, M.; SANTOS, J. V.; SALAMONI, A. T. Práticas ambientais em escolas públicas de Frederico Westphalen. Revista Eletrônica em Gestão, Educação e Tecnologia Ambiental - REGET. Revista do Centro do Ciências Naturais e Exatas. UFSM. Santa Maria. v. 14 n. 14, p. 2817- 2822, Set. 2013.

Taise Bomfim de Jesus

Possui graduação em Biologia pela Universidade Católica do Salvador (2001), mestrado em Geoquímica e Meio Ambiente pela Universidade Federal da Bahia (2005) e doutorado em Ecologia e Recursos Naturais pela Universidade Estadual do Norte Fluminense Darcy Ribeiro (2009). Atualmente é professora titular da Universidade Estadual de Feira de Santana. Membro do corpo docente dos seguintes Programas de Pós-Graduação: Modelagem em Ciências da Terra e do Ambiente e Mestrado Profissional em Rede para o Ensino das Ciências Ambientais. E-mail: taise@uefs.br.

\begin{abstract}
Alessandro Oliveira Andrade
Graduação em Ciências Biológicas pela Universidade Católica do Salvador (2003) e Mestre em Ensino das Ciências Ambientais pela Universidade Estadual de Feira de Santana (2021). Atualmente é professor da Secretaria de Educação do Estado da Bahia e Consultor Ambiental da Empresa Ambiental Brasil Consultoria e Treinamento Ltda. E-mail: alessandro.andrade@enova.educacao.ba.gov.br. ORCID: https://orcid.org/0000-0001-8370-0675.
\end{abstract}

\title{
Carlos Eduardo Veiga de Carvalho
}

Possui graduação em Ciências Biológicas pela Universidade Federal do Rio de Janeiro (1989), mestrado em Geociências (Geoquímica) pela Universidade Federal Fluminense (1992), doutorado em Geociências (Geoquímica) pela Universidade Federal Fluminense (1997), Pós-Doutorado no Leibniz Center for Tropical Marine Ecology (2010). Atualmente é Professor Associado 1 da Universidade Estadual do Norte Fluminense Darcy Ribeiro. Tem experiência na área de Geociências, com ênfase em Geoquímica Ambiental, atuando principalmente nos seguintes temas: metais pesados, peixe, contaminação, mercúrio e lagoas. E-mail: carvalho.cev@gmail.com. ORCID: https://orcid.org/0000$\underline{0002-7704-9588 .}$. 